\title{
A Securitização do Narcotráfico nos Estados Unidos e a influência no Brasil
}

\author{
The Securitization of Drug Trafficking in the United States and influence in \\ Brazil
}

Nerissa Krebs Farret ${ }^{1}$

\section{RESUMO}

O presente artigo tem por objetivo analisar a questão do combate ao narcotráfico nos Estados Unidos e Brasil através da ótica da Teoria da Securitização. Aplica-se essa teoria ao analisar o processo de politização e securitização do narcotráfico nos Estados Unidos da América e a influência que exerceu sobre a securitização do tema no Brasil, através de ações do Governo que culminaram no Plano Estratégico de Fronteiras.

Palavras-chave: Narcotráfico, Plano Estratégico de Fronteiras, Securitização.

\begin{abstract}
This article aims to analyze the issue of combating drug trafficking in the United States and Brazil through the lens of the Theory of Securitization. This theory is applied to analyze the process of politicization and securitization of drug trafficking in the United States and the influence exerted on the securitization of the issue in Brazil, through actions of the government that culminated in the Strategic Border Plan.
\end{abstract}

Keywords: Drug Trafficking, Strategic Border Plan, Securitization

\section{Introdução}

No contexto pós Guerra Fria e o consequente advento de um mundo sem as preocupações ligadas a Guerra, percebe-se a formação de um novo cenário internacional e a emergência de uma nova agenda de discussões. Essa nova agenda, se volta para questões que até então eram ofuscadas pelo conflito entre os Estados, fazendo-se notar

\footnotetext{
${ }^{1}$ Pós-Graduanda em História Contemporânea e Relações Internacionais, Pontifícia Universidade Católica do Paraná (PUC PR), Curitiba, Brasil.

Conjuntura Global, Vol.3, n. 4, out./dez., 2014, p. 226-232.
} 
também, a necessidade de novos paradigmas (saindo da análise realista até então preponderante) para analisar esse novo contexto que se compunha.

Assim, impulsionados por essa nova agenda de discussões, começa a se desenvolver na Europa, em 1985, a Escola de Copenhague. Segundo seus principais teóricos, Buzan, Waever e Wilde (1998) a escola começou seus estudos devido à insatisfação com a teoria realista, que abrangia as questões de segurança apenas no âmbito do Estado e de suas preocupações militares. Para eles, a discussão sobre segurança deveria ser ampliada, e abranger assuntos do setor político, societal, ambiental.

De acordo com a teoria trabalhada pela Escola de Copenhague, que leva o nome de Teoria da Securitização, o processo de securitização é o movimento que leva ameaças além das regras pré-estabelecidas pela política e enquadra um determinado assunto, seja como tipo especial de política - assunto politizado - seja como acima da política securitizado (Barry Buzan, Ole Waever e Jaap Wilde, 1998).

Assim, Waever (1995) inspira-se na "Teoria dos Atos de Linguagem", desenvolvida pelo filósofo John L. Austin, para analisar o processo comunicativo por meio do qual uma questão é transposta para a esfera da segurança. Com o auxílio da teoria da linguagem, é possível conceber a segurança como um ato de fala. Para o autor, a segurança não é objeto de interesse, como um signo que se refere a algo mais real, a fala em si é o ato, ou seja, ao dizer "segurança", um representante estatal faz referência a um acontecimento em uma área específica e assim demanda um direito especial para utilizar quaisquer meios que se fizerem necessários para evitá-lo.

Sendo assim, uma questão pode ser enquadrada como não politizada, politizada ou securitizada. Não politizada, quando o Estado não está relacionado à questão e sobre ela não envolverá um debate ou decisão pública. Politizada, quando a questão requisita uma decisão governamental e faz parte da política pública. Por fim, a questão é considerada securitizada quando apresenta uma ameaça existencial, requisitando medidas urgentes e justificando ações fora do processo político normal. A securitização é a versão extremada da politização (Silva, 2013).

Entre os novos temas discutidos no cenário internacional, o narcotráfico teve principal destaque nessa nova agenda do pós-guerra. É preciso observar, entretanto, que já era uma preocupação interna norte-americana desde meados da década de 1860/70. 
O que muda nesse novo contexto é a centralidade que o tema ganha, tanto nos EUA como no restante dos Estados, especialmente na América Latina.

\begin{abstract}
Em face do esvaziamento de ameaças tradicionais á segurança e do avanço do narcotráfico em praticamente todos os continentes, o mesmo passou a ser percebido como uma das mais importantes ameaças á segurança dos Estados, tendo se inserido na agenda política do continente americano de forma intensa, em razão de nele se situarem os principais produtores e maior mercado de cocaína, além de outras drogas ilegais (FILHO E VAZ, 1997, p. 20).
\end{abstract}

Assim, analisando o tráfico internacional de psicoativos, através do conceito de securitização defendido pela Escola de Copenhague, observa-se o avanço do tema nos Estados Unidos. Em meados dos anos 1860/70, como mencionado, a pressão de grupos para um maior rigor sobre o controle do uso de psicoativos aumenta e anos mais tarde, em 1906, é aprovada a Food and Drug Act. Essa lei não proibia, mas regulamentava a produção desses bens, exigindo condições de higiene adequadas e padronização nas indústrias financeiras.

Entretanto, observa-se aí o marco no qual o tema do narcotráfico passa a categoria de questão politizada, fazendo parte da política pública norte-americana. Com o avanço das preocupações com o narcotráfico e a postura proibicionista demonstrada pelos Estados Unidos em Conferências, como a de Xangai, realizada em 1909 e de Haia, que ocorreu em 1912, a pressão em torno do tema cresce e consequentemente, o Congresso Nacional aprova, em 1914, a Lei Harrison.

A Lei Harrison, criava a figura do traficante, aquele que produz e comercializa a droga psicoativa irregularmente, e a do viciado, aquele que a consome e necessita de tratamento médico. Em 1930, é criado o Food and Drug Administration (FDA) e o Federal Bureau of Narcotics (FBN), demonstrando o maior aprofundamento da questão da droga em solo norte-americano.

Anos mais tarde, são aprovadas sucessivamente duas leis: a primeira, em 1951, conhecida como Boggs Act e a segunda, em 1956, como Narcotics Control Act. Condensando todas as leis aprovadas desde a Lei Harrison, os traficantes sem antecedentes criminais teriam pena de cinco anos de prisão, e traficantes maiores que comercializassem drogas para menores de idade teriam a pena de morte como punição.

Em 1961, ocorre a Convenção Única sobre Drogas, um marco no posicionamento repressor norte-americano, mas, é no início dos anos 80, que os Estados Unidos 
observam um elevado aumento na demanda por drogas e consequentemente, aumento nos problemas sociais decorrente da utilização desses psicoativos. O Governo Reagan passa a ser pressionado pela população para agir de forma mais ativa nessa questão, adotando medidas mais rigorosas de repressão e controle sobre o tráfico e uso de drogas. Esse fato foi concretizado pelo presidente ao declarar "Guerra às Drogas", securitizando, por meio do discurso, o narcotráfico e passando a encará-lo como um tema emergencial e uma ameaça a soberania de qualquer Estado que possuísse atividade "narcotraficante".

Entre as medidas tomadas para contenção do aumento do narcotráfico em solo norte-americano, destacam-se a busca pela redução da oferta, ou seja, adoção de políticas voltadas para outros Estados. Nesse caso, especialmente os países latinos, por serem reconhecidamente os principais produtores.

No Brasil, a trajetória de proibição às drogas começa, de fato, a partir da década de 80 e fortemente influenciada pela política norte-americana. Essa influência acontece principalmente de duas formas. A primeira, através de Convenções e Conferências Internacionais, como a Convenção Única sobre Drogas em 1961, cujas decisões foram internalizadas pelo Brasil em 1967 e a Conferência de Cúpula de 1990, realizada em Cartagena. A segunda forma, que pode ser percebida mais claramente a partir da declaração de "Guerra às Drogas", se dá através de ações que condicionam ajuda econômica por parte dos EUA e de órgãos internacionais ao seguimento das diretrizes repressoras norte-americanas.

Um exemplo disso é o Processo de Certificação, criado pelo Presidente Clinton e aprovado pelo Congresso no qual se instituía, no início do mês de março de cada ano, uma lista dos países que não fizeram esforços nos campos de combate à produção e ao tráfico de drogas. Caso os países aparecessem nessa lista, deixariam de receber auxílio financeiro dos Estados Unidos e também, comprometeriam sua posição frente às instituições internacionais, como o Fundo Monetário Financeiro. Essa técnica influenciava e direcionava as ações dos Estados, especialmente aqueles como o Brasil e demais países latino-americanos que dependiam de apoio e ajuda externa norteamericana.

Assim, observa-se na trajetória de combate às drogas no Brasil, um aumento gradativo nos mecanismos e ações políticas repressoras devido à influência dos Estados Unidos. Na década de 80, de acordo com Rodrigues (2004) o Comando Vermelho e Conjuntura Global, Vol.3, n. 4, out./dez., 2014, p. 226-232. 
outras organizações narcotraficantes começam a se instalar nos morros do Rio de Janeiro, o que seria mais tarde conhecido por "Governo Paralelo". Nessa mesma época, segundo Filho e Vaz (1997) devido à extensão e porosidade de suas fronteiras, o Brasil entra definitivamente na rota do tráfico de drogas e passa a atuar nesse cenário como país de trânsito.

Analisando através da ótica da Teoria da Securitização, no Brasil, a questão do narcotráfico passa a ser securitizada juntamente com a questão das fronteiras. Em 1990, foi aprovado o SIVAM - Sistema de Vigilância da Amazônia, entretanto, só foi posto em prática a partir do ano de 2002. Entende-se esse, como o primeiro passo para a securitização do narcotráfico no Brasil e uma preocupação maior com a fronteira brasileira.

Entretanto, é importante destacar que o narcotráfico já havia se tornado um tema politizado muito antes de desenvolverem-se políticas pensadas na questão do controle da entrada de psicoativos por meio da fronteira. Em 1967, se deu a incorporação das decisões da Convenção Única sobre drogas e o consequente endurecimento da pena para traficantes e viciados.

Mais tarde, em 1976, é aprovada a Lei dos Tóxicos, que entra em sintonia com a postura repressora dos Estados Unidos e demonstra a disposição brasileira em se alinhar com esse tipo de política. Essa lei só seria substituída em 2006, após muito se discutir e pensar a melhor forma de abordar o problema do narcotráfico no Brasil. Um avanço da Lei de 2006 é o fato de encarar a questão das drogas como um problema de saúde pública, instituindo o Sistema Nacional de Políticas Públicas sobre Drogas (Sisnad). 0 qual era responsável por prescrever medidas para prevenção do uso indevido, atenção e reinserção social de usuários e dependentes das drogas, estabelecendo normas para repressão à produção não autorizada e ao tráfico ilícito de drogas.

Dois anos antes, observam-se os primeiros sinais do processo de securitização do narcotráfico no Brasil, especialmente na região de fronteira, com a regulamentação da Lei do Abate.

A possibilidade de que aviões sejam abatidos aumentou, potencialmente, o envolvimento de militares no combate ao narcotráfico, uma vez que caberia à Força Aérea a execução de missões desse tipo (RODRIGUES, 2012, p. 79). 
Destaca-se assim, o caráter emergencial e definitivo com que a Lei do Abate trataria aviões suspeitos de tráfico na fronteira brasileira e mostra mais um avanço em direção à securitização do assunto.

Um ano antes da posse da Presidente Dilma Rousseff, ocorre à regulamentação de um dispositivo presente na Constituição de 1988, que davam poder de polícia aos militares em áreas de fronteira, ou seja, as Forças Armadas poderiam revistar veículos, pessoas e realizar prisões em flagrante. Esse fato corrobora a ideia de que a Lei do Abate inicia um processo de securitização do narcotráfico, já tratado como um tema politizado anteriormente.

Assim, ao assumir o Governo, a Presidente Dilma securitiza de vez o assunto do narcotráfico, criando, por meio de um Decreto presidencial, o Plano Estratégico de Fronteiras (PEF). O Plano Estratégico de Fronteiras conta com duas vertentes principais. A primeira delas é a Operação Sentinela, coordenada pelo Ministério da Justiça e que reúne a Polícia Federal, a Polícia Rodoviária Federal e também a Força Nacional de Segurança. A Operação Sentinela tem caráter permanente, atuando no dia a dia e fiscalizando as fronteiras.

A segunda vertente do Plano é a Operação Ágata. De acordo com Silva (2013), a Ágata é a real e específica materialização da ameaça por se tratar de uma ação pontual, com prazo para começar, terminar, por ser delimitada espacialmente e ter o caráter de ação imediata para o combate ao tráfico de drogas. Ou seja, é a Operação Ágata que apresenta claramente o caráter de securitização do narcotráfico na fronteira brasileira.

Durante a Ágata, milhares de militares e agentes da polícia federal fiscalizam a fronteira brasileira, revistando veículos e pessoas. Os militares são responsáveis também, por prestar serviços assistencialistas às populações, oferecendo vacinações, atendimentos médicos e odontológicos. Até o presente, foram organizadas oito Operações Ágata.

Logo, observa-se que a securitização do narcotráfico nos Estados Unidos começou através do endurecimento da legislação sobre drogas e culminou na declaração de “Guerra ás Drogas” pelo presidente Reagan, adotando atitudes cada vez mais radicais para controlar o narcotráfico. Essa postura influenciou o Brasil a adotar a mesma posição no que tange ao tráfico internacional de psicoativos, levando a um processo de securitização que inicia na Lei do Abate e culmina no Plano Estratégico de Fronteiras, com destaque para a Operação Ágata.

Conjuntura Global, Vol.3, n. 4, out./dez., 2014, p. 226-232. 


\section{Referências}

BUZAN, Barry. People, states and fear: an agenda for international security studies in the post-Cold War era. Colorado: Lynne Rienner, 1991.

BUZAN, Barry; HANSEN, Lene. Evolution of international security studies. Cambridge: Cambridge University, 2009.

BUZAN, Barry; WAEVER, Ole. Regions and Powers: the structure of International Security. Cambridge: Cambridge University Press, 2003.

BUZAN, Barry; WAEVER, Ole; WILDE, Jaap de. Security: a new framework for analysis. Boulder: Lynne Reinner, 1998.

RODRIGUES, Thiago. Narcotráfico: Uma Guerra na Guerra. 2. ed. São Paulo: Desatino, 2012.

FILHO, Argemiro Procópio; VAZ, Alcides Costa. O Brasil no contexto do narcotráfico internacional. Rev. bras. polít. int. v.40 n.1 Brasília jan./jun. 1997.

SILVA, Caroline Cordeiro Viana e. Segurança internacional e novas ameaças: a securitização do narcotráfico na fronteira brasileira: Curitiba, 2013. $126 f$. 